\title{
Correction to: Effect of microbial sanitizers for reducing biofilm formation of Staphylococcus aureus and Pseudomonas aeruginosa on stainless steel by cultivation with UHT milk
}

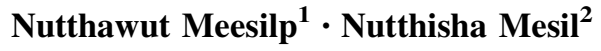

(C) The Korean Society of Food Science and Technology 2019

\section{Correction to: Food Sci Biotechnol (2019) 28(1):289-296 \\ https://doi.org/10.1007/s10068-018-0448-4}

The article "Effect of microbial sanitizers for reducing biofilm formation of Staphylococcus aureus and Pseudomonas aeruginosa on stainless steel by cultivation with UHT milk", written by "Nutthawut Meesilp and Nutthisha Mesil", was originally published electronically on the publisher's Internet portal (currently SpringerLink) on 11 August 2018 with open access.

With the author(s)' decision to step back from Open Choice, the copyright of the article changed on 6 December 2019 to (c) The Korean Society of Food Science and Technology 2019 and the article is forthwith distributed under the terms of copyright.

The original article has been corrected.

The original article can be found online at https:// doi.org/10.1007/s10068-018-0448-4.

Nutthawut Meesilp

nutthawutm@hotmail.com

1 Department of Applied Biology, Faculty of Science and Liberal Art, Rajamangala University of Technology Isan, Nakhon Ratchasima 30000, Thailand

2 Srinagarind Hospital, Khon Kaen University, Khon Kaen 40002, Thailand 